\title{
Validation and clinical interpretability of PsAID - psoriatic arthritis impact of disease
}

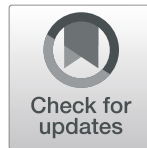

\author{
Elziane da Cruz Ribeiro e Souza ${ }^{1 *}$ D, Sueli Coelho da Silva Carneiro², Michel Alexandre Yazbek ${ }^{3}$, \\ Rita de Cássia Menin ${ }^{4}$, Cristiano Barbosa Campanholo ${ }^{5}$, Jamille Nascimento Carneiro ${ }^{6}$, \\ Carlos Henrique Martis da Silva ${ }^{1}$ and Roberto Ranza ${ }^{1}$
}

\begin{abstract}
Background: Psoriatic arthritis (PSA) is a chronic inflammatory disease of widely varying presentation, which determines functional and psychological impairment, with a high negative impact on patients' quality of life. Therefore, knowing the patient's perception of their health status is of fundamental importance for understanding the real impact of PSA. Given this context, the European League Against Rheumatism (EULAR) recently developed the Psoriatic Arthritis Impact of Disease (PSAID) - instrument to specifically assess the impact of PsA for the patient.

Objective: Validate the brazilian portuguese version of PsAID-12 (Psoriatic Arthritis Impact of Disease) and to verify its interpretability in clinical practice, through its relation with measures of psoriatic arthritis activity.

Methods: A multicenter cross-sectional study, which recruited 160 patients, who met the Classification criteria for Psoriatic Arthritis (CASPAR), in six Brazilian centers of rheumatology. Reliability was assessed by Cronbach's alpha coefficient and by the intraclass correlation coefficient (ICC). The construct validity was evaluated by exploratory factorial analysis and also by Spearman correlation with other PROMs and measures of disease activity evaluation.

Results: Of the total number of participants, 50\% were female, with a mean age (SD) of $54.0 \pm 11.2$ years; $68 \%$ had only peripheral arthritis and $32 \%$ had pure or mixed axial involvement. The majority $(67.7 \%)$ of the patients were using biological treatment. The reliability of internal consistency (alpha-Cronbach $=0.93$ ) and test-retest $(I C C=0.996)$ were good. Factor analysis revealed two factors, named physical and psychosocial, which included the skin evaluation item. PSAID-12 correlated significantly with other PROMs, demonstrating good construct validity. PsAID12 was also significantly associated with the disease activity assessment instruments (DAS28-ESR, ASDAS, and BASDAI) and the MDA status: "Minimum Disease Activity". Fibromyalgia did not significantly affect the final PsAID-12 score.
\end{abstract}

Conclusion: The brazilian version of PSAID-12 has been shown to be a reliable and valid measure of the impact of the disease in patients with psoriatic arthritis. Moreover, it associated significantly with the scores of disease activity assessment.

Keywords: PsAID-12, Psoriatic arthritis, Minimal disease activity, PROM, Quality of life

\footnotetext{
* Correspondence: elzianecruz.reumatologia@gmail.com

1 Department of Rheumatology, Federal University of Uberlândia, Av. Mato

Grosso, 3395, 302, Umuarama, Uberlândia, Minas Gerais 38405-314, Brazil

Full list of author information is available at the end of the article
}

(c) The Author(s). 2020 Open Access This article is licensed under a Creative Commons Attribution 4.0 International License, which permits use, sharing, adaptation, distribution and reproduction in any medium or format, as long as you give appropriate credit to the original author(s) and the source, provide a link to the Creative Commons licence, and indicate if changes were made. The images or other third party material in this article are included in the article's Creative Commons licence, unless indicated otherwise in a credit line to the material. If material is not included in the article's Creative Commons licence and your intended use is not permitted by statutory regulation or exceeds the permitted use, you will need to obtain permission directly from the copyright holder. To view a copy of this licence, visit http://creativecommons.org/licenses/by/4.0/. 


\section{Introduction}

Psoriatic arthritis (PsA) is an inflammatory, chronic disease with a complex and heterogeneous presentation. Its various domains include: peripheral arthritis, axial involvement, enthesitis, dactylitis, uveitis, cutaneous and nail psoriasis, as well as the association with comorbidities such as metabolic syndrome, obesity, cardiovascular disease and depressive disorder [1-4].

The prevalence of PsA varies among populations, but a study conducted in a large cohort in Brazil found that it affects $33 \%$ of individuals with psoriasis (PSO) [1].

This diversity of the clinical spectrum of PsA, activity and potential damage of the disease determine functional and psychological impairment, with a high negative impact on patients' quality of life. Likewise, they hinder the overall evaluation of affected individuals [5-7].

In recent years, it has been recognized that, in chronic diseases and especially in multifaceted rheumatological conditions such as PsA, the patient's perception of his health status is of fundamental importance in terms of understanding the real impact of the disease and the shared definition of the treatment target $[8,9]$. This became even more relevant when studies in patients with psoriatic arthritis had shown divergences between the doctor's and patient's views on disease activity [10]. Since then, the development of Patient-Reported Outcome Measures (PROM) in PsA has been encouraged. They are taken directly from the patient and evaluate how they feel or act in relation to their health condition. These measures reflect the burden of disease for the individual $[11,12]$. PROMs are considered a reliable indicator of baseline status and disease change during treatment and are predictive of long-term outcomes $[11,13]$.

However, until recently there were no specific PROMs for PsA and studies based on the opinion of psoriatic patients used generic quality of life and disease impact assessment tools or those developed for other diseases such as rheumatoid arthritis [14]. Therefore, they didn't contemplate the peculiar variety of domains of PsA.

Given this context and motivated by the need to know the impact of PsA from a patient's perspective, the European League Against Rheumatism (EULAR) recently developed the Psoriatic Arthritis Impact of Disease (PsAID) - PROM specific PsA - in two versions: one composed of 12 health domains to be used in clinical practice (PsAID-12) and a shorter version with nine domains to be used in clinical trials (PsAID-9) [8, 15]. PsAID scores had satisfactory psychometric properties in a preliminary international validation study, but the authors recognized the need for validation in other cohorts [8]. After a transcultural translation and adaptation process that followed internationally accepted standards [16]. The PsAID-12 version in brazilian portuguese was made available on the official EULAR website [15].
However, the psychometric validation of this Brazilian version has not yet been performed.

After the creation of the PSAID-12, it became also important to verify how this instrument, a disease impact measure, is related the disease activity measures to understand its usefulness in clinical practice [17].

Currently, a range of composite indices is available to assess disease activity in PsA, and there is no consensus on which is best, since each has specific advantages and limitations. However, MDA (Minimal Disease Activity) stands out among them, since it is a simple, easy-to-use tool that covers a greater number of PsA domains, including skin, and mainly because it has been applied as a target for treatment decision making [18].

Based on the above, the objectives of the present study were:

- validate the brazilian portuguese version of PsAID-12 and verify its interpretability in clinical practice.

\section{Material and methods Study and participants}

A cross-sectional, multicenter study that recruited consecutively 160 patients from the outpatient clinics of six rheumatology centers in Brazil, from July 2017 to April 2018, in real clinical settings. Inclusion criteria were adults older than 18 years, literate, with a diagnosis of PsA according to the classification criteria CASPAR (Classification Criteria for Psoriatic Arthritis) [19]. Patients with other skin disease and/or other non-PsA related inflammatory joint diseases were excluded.

For the test-retest evaluation, 16 patients (10\% of the sample) who had no indication of change in PsA treatment filled PsAID-12 between 7 and 10 days after the first evaluation.

All participants signed the Free and Informed Consent Term and the project was approved by the Human Research Ethics Committee of the Uberlandia Federal University, under the "Number of Opinion: 2,042,168".

\section{Data collect}

Data collection was performed during a single outpatient visit by the research rheumatologist of each center. The patient record was reviewed in a targeted manner to record the CASPAR criteria [19] and to search for clinical information on both $\mathrm{PsO}$ and PsA, including psoriasis type, radiological exam parameters, pattern of impairment and duration of PsA. The classification of PsA in peripheral, axial and mixed was performed using rheumatological clinical evaluation and findings from appropriate radiographic exams.

A questionnaire specifically designed for this study was used to collect, through patient interview, the following socio-demographic parameters: age, self-declared race, sex, educational level, marital status, employment 
status, and body mass index (BMI). Habits of life (smoking and alcoholism), the presence of extra-articular manifestations and the presence of comorbidities more associated with PsA (systemic arterial hypertension (SAH), diabetes mellitus (DM), dyslipidemia, depressive disorder, fibromyalgia and metabolic syndromes (MS)]. The diagnosis of MS was defined according to the criteria of The National Cholesterol Education Program (NCEP) Adult Treatment Panel III (ATP III) [20, 21].

Inflammatory acute phase markers [Erythrocyte Sedimentation Rate (ESR) $(\mathrm{mm} / \mathrm{h})$ and Quantitative C - Reactive Protein $(\mathrm{CRP})(\mathrm{mg} / \mathrm{L})]$ from last month were recorded for calculating the disease activity scores.

After the interview, participants were asked to complete the PsAID-12, the visual analogue scale of 10 $\mathrm{cm}$ for both pain (VAS pain) and for the overall evaluation of the disease (overall patient VAS), in addition to the other PROMs used in the of the PsA: Medical Outcome Study 36-item Short Form Health Survey (SF-36) [22], Health Assessment Questionnaire-Disability Index (HAQ-DI) [23] and Dermatology Life Quality Index (DLQI) [24].

All patients were assessed by the rheumatologist, with the following variables: number of tender (range 0-68) and swollen joints (range 0-66); counting of fingers with dactylitis, evaluation of enthesitis by the Research Consortium of Canada Enthesitis Index (SPARCC) [25], axial examination and evaluation of the severity of the cutaneous manifestations estimated by PASI (Psoriasis Area Severity Index) [26].

After completing the questionnaires and the clinical examination, the following scores were calculated for disease activity: DAS-28 ESR (Disease Activity Score 28 joints); DAPSA (Disease Activity in Psoriatic Arthritis index) [27] ASDAS-ESR and CRP (Ankylosing Spondylitis Disease Activity Score), Bath Ankylosing Spondylitis Disease Activity Index (BASDAI) [28] and Minimal Disease Activity (MDA) [18].

The scores for axial disease activity (ASDAS, BASDAI) were calculated only for patients with axial impairment and, similarly, DAS-28 ESR and DAPSA were calculated only in patients with peripheral or mixed impairment.

\section{Instrument}

PsAID-12 is a questionnaire derived from the patient, composed of 12 health domains, each evaluated by a single question regarding the symptoms and physical and psychosocial difficulties related to PsA that the patient presented in the last 7 days. The response is given on a numerical scale, with a range from 0 to 10 , in which higher results indicate a greater impact of the disease. The final point score is calculated using software available on the EULAR website and also ranges from 0 (best status) to 10 (worst status). The proposed cut-off value for interpreting the PsAID score is 4 , with a score $<4$ being an acceptable symptom state [8].

\section{Psychometric tests and statistical analysis}

Descriptive statistics were used to describe sociodemographic and clinical characteristics of the participants. Quantitative variables were presented by mean and standard deviation or interquartile range and median. Qualitative variables were described by absolute and relative frequencies.

\section{Reliability}

The reliability of the internal consistency of PsAID-12 was evaluated by Cronbach's alpha coefficient. The testretest reliability was analyzed by the intraclass correlation coefficient (ICC) to determine the agreement between the two evaluations. Cronbach's alpha and ICC values above 0.7 indicate, respectively, good internal consistency and concordance [29].

\section{Construct validity}

To evaluate the construct validity (correlation between PsAID-12 scores with other already validated PROMs and assessment of disease activity instruments), the Spearman correlation test was applied.

\section{Exploratory factorial analysis}

A factorial analysis of components was performed using axle extraction with varimax rotation method, which maximizes the independence of the factors. An eigenvalue criterion greater than 1.0 was used to select the factors. Factorial loads that find values of at least $0.3 \mathrm{ob}-$ tain a minimum level to remain in the instrument and those with values of 0.5 or more are considered practically significant [30].

\section{PsAID-12 association with MDA}

The MDA, a composite status of disease activity in PsA, consists of seven criteria: swollen and tender joint count $\leq 1$, enthesitis $\leq 1$, patient global activity on a $0-10$ scale $\leq 2$, patient pain on a $0-10$ scale $\leq 1.5$, HAQ-DI $\leq 0.5$, PASI $\leq 1$ or BSA (Body Surface Area) $\leq 3$. From this, three classifications are possible for the activity status of the PsA: status MDA (Minimal Disease Activity: patients who meet $\geq 5 / 7$ criteria, VLDA status (Very Low Disease Activity: patients meeting $7 / 7$ criteria and Non-MDA: patients fulfilling $\leq 4$ criteria) [18].

In order to compare the PSAID-12 scores between the groups (MDA, VLDA and Non-MDA), the MannWhitney and Kruskal-Wallis tests (complemented by Dunn) were applied to the dichotomous and polytomy variables, respectively. 
The significance level adopted was 5\% $(p<0.05)$ and the analyzes were performed in the SPSS program version 21.0.

\section{Results}

Patients sociodemographic and clinical characteristics are described in Table 1. Of the 160 patients included in the study, $50 \%$ were female, with a mean age (SD) of $54.0 \pm 11.2$ years; almost half of the participants had low educational level and 33\% were away from their work activities or retirees due because of PsA.

Regarding psoriatic disease, the median duration (P25P75) of PsA was 8 [5-14] years and $72 \%$ of patients had some related radiological alteration. Regarding the pattern of PsA involvement, of the total number of patients, $68 \%$ had only peripheral arthritis and $32 \%$ had pure or mixed axial envolvement. Enthesitis was found in 33 patients (20\%) and dactylitis in 21 (13.1\%). The majority (67.7\%) of the patients were on biological treatment.

Most of our cohort had active disease: $56 \%$ had DAPSA result moderate or high; $54 \%$ had moderate or high peripheral joint disease, as assessed by DAS28-ESR, and more than $75 \%$ of patients with axial disease had ASDAS-ESR and ASDAS-CRP classified as high or very high disease activity. Similarly, most patients had BASDAI $>4.54 \%$ had moderate or high peripheral joint disease, as assessed by DAS28-ESR, and more than $75 \%$ of patients with axial disease had ASDAS-ESR and ASDASCRP classified as high or very high disease activity. Similarly, most patients had BASDAI $>4$.

Regarding comorbidities, $43.8 \%$ of the patients were overweight and $34 \%$ were obese, according to their BMI; $51 \%$ had a diagnosis of SAH, 66\% dyslipidemia and $62.5 \%$ MS. Of note, the criterion of abdominal obesity was present in almost $84 \%$ of these patients. The minority presented a diagnosis of fibromyalgia (17.5\%).

\section{Reliability}

The internal consistency of PsAID 12 measured by Cronbach's $\alpha$ coefficient was 0.93 and test-retest reliability showed an ICC of 0.996 (95\% CI: 0.989-0.999; $p=0.001$ ).

\section{Construct validity}

The exploratory factorial analysis was performed to examine the factorial structure of the Brazilian version of PsAID-12. The analysis revealed a result of two factors named physical (composed of 8 items) and psychosocial (composed of 4 items), as described in Table 2.

Applying the Spearman correlation test, a strong correlation of PsAID-12 with the other PROMs was observed, demonstrating good construct validity, as described in Table 3.
Remarkably, PsAID-12 also correlated significantly with disease activity assesed with the instruments DAS28-ESR, ASDAS, BASDAI, DAPSA and with composite status MDA - Table 3.

Patients with moderate to high disease activity, as defined by DAPSA, presented significantly higher PsAID12 scores (Mann-Whitney test, $p<0.001$ ), as can be seen in Fig. 1. Likewise, the greater the axial disease activity measured by both ASDAS and BASDAI, greater the PsAID-12 all domains scores and total score (Table 4).

Overall, 15.1\% of patients achieved MDA status and $10.1 \%$ in VLDA status versus $74.8 \%$ in non-MDA status. Interestingly, the MDA criteria less frequently achieved by the patients were the visual analogue pain scale and the patient's overall disease score, which were only achieved by 15 and $24 \%$ of the patients, respectively.

Analyzing the median (P25-P75) of the total PsAID-12 score according to MDA status, patients in MDA and VLDA showed a significantly lower disease impact with a score of $2.2(1.4-3.6)$ and $0.5(0.2-0.9)$ respectively versus $4.7(3.0-6.4)]$ for non-MDA, with $p<0.001$. Statistically significant differences were also observed between the MDA/VLDA and non-MDA groups for all domains of PsAID-12 $(p<0.001)$ Table 5.

In our sample, there was a statistically significant positive association of BMI with the domains of Pain, Fatigue, Difficulty for Work and Leisure, Physical Capacity, Discomfort, Social Participation, Depression and PsAID12 total score, that is, the higher the degree of obesity, higher scores in these areas.

There was a tendency of female patients $(\mathrm{MD}=3.9$, P25-P75: 2.0 to 6.3) having a higher PsAID-12 scores than males (MD = 3.6, P25- P75: 1.3-5.3, $p=0.086)$.

The PsAID-12 score didn't change significantly when stratified by the presence or absence of radiological alteration, by the use of biological treatment or by the presence of fibromyalgia, except for the pain domain, significantly higher in the group of patients with fibromyalgia $(p=0.026)$.

\section{Discussion}

Our study confirmed the reliability of the brazilian version of PsAID-12, demonstrated good internal consistency and good construct validity. In addition, it introduced some new PsAID-12 associations with clinical variables and disease activity scores.

Equal distributions of PsA between the sexes as well as the mean age found in our sample are in agreement with data available in the literature $[1,31,32]$.

It is noteworthy that almost half of our patients had a low educational level and yet were able to complete PsAID-12 without loss. This allows us to infer that it presents an accessible, easy-to-understand language and that the shortest model based on objective responses is 
Table 1 Sociodemographic and clinical characteristics of study participants

\begin{tabular}{ll}
\hline Variables & $\boldsymbol{n}=160$ \\
\hline $\begin{array}{l}\text { Age (years) - mean } \pm \text { SD } \\
\text { Gender }-\mathrm{n}(\%)\end{array}$ & $54.0 \pm 11.2$ \\
$\quad$ Female & $80(50.0)$ \\
$\quad$ Male & $80(50.0)$ \\
Race self-declaration - $\mathrm{n}(\%)$ & \\
$\quad$ White & $99(61.9)$ \\
Black & $14(8.8)$ \\
Mulatto & $37(23.1)$ \\
Other & $10(6.2)$
\end{tabular}

Educational level - $\mathrm{n}(\%)$

Elementary school incomplete

Elementary school complete

Secondary school

College

Postgraduate

Current employment status $-\mathrm{n}(\%)$

Active

Away due to PsA

Retired due to PsA

Retired or away for other reasons

Unemployed

Classification of BMI - n (\%)

Eutrophic

Overweight

Obesity

Smoker - n (\%)

Alcoholic - $\mathrm{n}(\%)$

Metabolic syndrome

Comorbidities

Systemic Arterial Hypertension
Diabetes Mellitus
Dyslipidemia
Depressive Disorder
Fibromyalgia
Duration of cutaneous disease/
psoriasis (years) - median (P25-P75)
Time of PsA symptoms (years) - median (P25-P75)
Type of psoriasis - n (\%)
Plaque
Palm plantar
Others
Onicopathy - n (\%)
Current treatment - n (\%)
Biological

52 (32.5)

$26(16.3)$

56 (35.1)

21 (13.2)

5 (3.1)

$66(41.3)$

33 (20.6)

$20(12.5)$

31 (19.4)

$10(6.3)$

35 (21.9)

$70(43.8)$

55 (34.4)

24 (15.0)

19 (11.9)

$100(62.5)$

$82(51.3)$

$34(21.3)$

$106(66.3)$

$31(19.4)$

$28(17.5)$

$18(8-27)$

$8(5-14)$

$142(88,8)$

$10(6,3)$

$8(5,1)$

$54(33,8)$

$107(66,9)$

Table 1 Sociodemographic and clinical characteristics of study participants (Continued)

\begin{tabular}{ll}
\hline Variables & $\boldsymbol{n}=160$ \\
\hline Joint count with edema - median (P25-P75) & $1(0-3)$ \\
Counting of joints with painful - median (P25-P75) & $2(0-5)$ \\
Enthesitis (SPARCC $\geq 1)$ - n (\%) & $33(20.6)$ \\
Radiographic changed - n (\%) & $115(71.9)$ \\
PASI $\leq 1-n(\%)$ & $66(41.3)$ \\
Type of PsA involvment - n(\%) & \\
Peripheral & $109(68,1)$ \\
$\quad$ Axial & $3(1,9)$ \\
$\quad$ Mixed & $48(30,0)$ \\
\hline
\end{tabular}

SPARCC Spondyloarthritis Research Consortium of Canada Enthesitis Index. PASI Psoriasis Area Severity Index

more appropriate for low educational level populations, as demonstrated in other instrument validation studies [33].

The reliability of the internal consistency and reproducibility of the Brazilian version of PsAID-12 were considered adequate, since both the Cronbach's alpha value and the ICC values were higher than 0.7 , which indicates good internal consistency and concordance [29].

In the analysis of construct validity, it was observed that the highest correlations were between PsAID-12 and other PROMs, followed by composite indices (physician and patient opinion), in comparison with objective evaluations, based only on the physician opinion, such as PASI, painful and swollen joints, and SPARCC. A similar result was found in the validation study of PsAID in the United Kingdom [32]. This data confirms the importance of the inclusion of PROMs in the overall evaluation of PsA, in order to minimize divergences between the opinions of the physician and the patient.

The factorial analysis distinguished two components in the main structure of the questionnaire. The first one

Table 2 Exploratory factor analysis of the Brazilian version of PsAID-12

\begin{tabular}{lll}
\hline Domains PsAID-12 & Physical & Psychosocial \\
\hline Pains & $\mathbf{0 . 8 5 0}$ & 0.170 \\
Fatigue/Tiredness & $\mathbf{0 . 7 2 9}$ & 0.195 \\
Skin Problems & 0.150 & $\mathbf{0 . 7 1 0}$ \\
Work and / or leisure activity & $\mathbf{0 . 8 3 8}$ & 0.274 \\
Physical Ability & $\mathbf{0 . 8 6 7}$ & 0.244 \\
Discomfort & $\mathbf{0 . 8 1 1}$ & 0.401 \\
Sleep disturbance & $\mathbf{0 . 6 5 6}$ & 0.396 \\
Dealing with the disease & $\mathbf{0 . 6 8 5}$ & 0.419 \\
Anxiety/Fear/Uncertainty & $\mathbf{0 . 6 0 8}$ & 0.503 \\
Embarrassment and/or shame & 0.184 & $\mathbf{0 . 8 4 3}$ \\
Social Participation & 0.402 & $\mathbf{0 . 7 2 2}$ \\
Depression & 0.490 & $\mathbf{0 . 6 6 9}$ \\
\hline
\end{tabular}


Table 3 Association of PSAID-12 with other PROMs and indices of disease activity (spearman correlation coefficient)

\begin{tabular}{lr}
\hline Variables & PSAID-12 \\
\hline HAQ-DI & $0.657^{* * *}$ \\
SF-36 (Physical Component) & $-0.756^{* * *}$ \\
SF-36 (Mental Component) & $-0.701^{* * *}$ \\
MDA & $-0.667^{* * *}$ \\
DLQI & $0.474^{* * *}$ \\
PASI & $0.288^{* *}$ \\
DAS 28 & $0.443^{* * *}$ \\
ASDAS ESR & $0.671^{* * *}$ \\
ASDAS CRP & $0.645^{* * *}$ \\
BASDAI & $0.683^{* * *}$ \\
PGA skin & $0.463^{* * *}$ \\
PGA joint & $0.748^{* * *}$ \\
VAS global patient & $0.684^{* * *}$ \\
VAS patient pain & $0.734^{* * *}$ \\
Counting painful joints & $0.300^{* * *}$ \\
Counting swollen joints & $0.319^{* * *}$ \\
DAPSA & $0,610^{* * *}$ \\
\hline PSAID Psoriatic Arthritis Impact of Disease, HAQ-DI Health Assessment \\
Questionnaire Disability Index, SF-36 Medical Outcomes Study 36 - Item \\
Short - Form Health Survey, MDA minimal disease activity, DLQI \\
Dermatology life Quality Index, PASI Psoriasis Area Severity Index, DAS 28 \\
Disease Activity Score 28, ASDAS Ankylosing Spondylitis Disease Activity \\
Score, CRP C Reactive Protein, ESR Erythrocyte Sedimentation Rate, BASDAl \\
Bath Ankylosing Spondylitis Activity Index, PGA Patient Global Assessment, \\
VAS Visual Analog Scale, SPARCC Spondyloarthritis Research Consortium of \\
Canada Enthesitis Index, DAPSA Disease Activity in Psoriatic Arthritis index \\
* $p<0.05 ; *$ * $p$ 0.01; *** $p<0.001$ & \\
&
\end{tabular}

related to the physical impact of PsA (pain, fatigue, ability to work and leisure, physical capacity, discomfort, altered sleep and dealing with the disease). The second factor was related to the psychosocial sphere (embarrassment and/or shame, social participation, depression and skin problems). The presence of the item "skin problems" related to the psychosocial sphere can be justified by the significantly higher association of psoriasis with depression and social participation impairment, already demonstrated in the literature [34, 35].

The item evaluating "anxiety, fear and uncertainty" presented very similar factor loads between the two factors, being 0.608 in the physical factor and 0.503 in the psychosocial factor. Since factor loads above 0.5 are already considered to be practically significant, it can be interpreted as being associated with both factors [34]. This is in accordance with data already published that point out that the physical component of PsA, mainly chronic pain and discomfort, are also related to the psychological impact of the disease [7].

In recent years, efforts to define the most appropriate treatment target for PsA have been great in order to achieve the best control of disease activity and improve the impact on patient quality of life. In this sense, several composed indices with both objective (physician's perception) and subjective evaluation (patient's perception) were developed; however, none of them was created with the substantial involvement of the patient, limiting, therefore, the global analysis of PsA from his perspective.

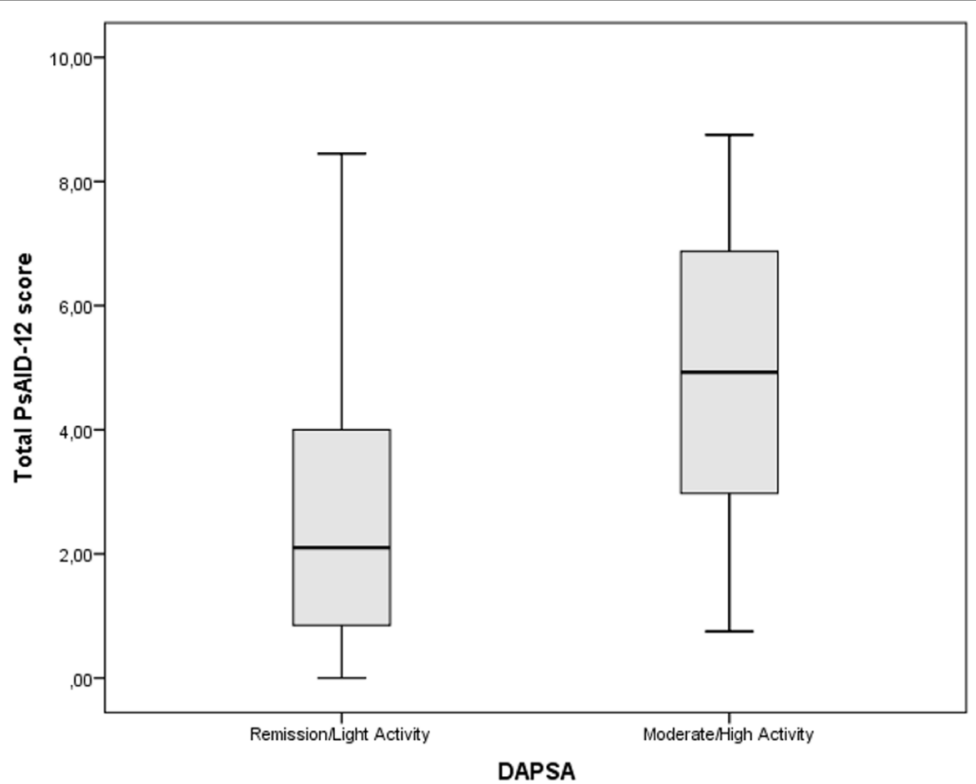

Mann-Whitney test; $p<0.001$

PsAID-12 - Psoriatic Arthritis Impact of Disease. DAPSA - Disease Activity in Psoriatic Arthritis index.

Fig. 1 Association of DAPSA with PSAID-12 score 
Table 4 Association of axial disease activity, measured by the ASDAS and BASDAI scores, using the PSAID-12, using Spearman's correlation coefficient

\begin{tabular}{llll}
\hline Domains PSAID & ASDAS CRP & ASDAS ESR & BASDAI \\
\hline Pains & $0.594^{* * *}$ & $0.540^{* * *}$ & $0.594^{* * *}$ \\
Fatigue/Tiredness & $0.599^{* * *}$ & $0.516^{* * *}$ & $0.664^{* * *}$ \\
Skin Problems & $0.529^{* * *}$ & $0.485^{* * *}$ & $0.537^{* * *}$ \\
Work and/or leisure activity & $0.548^{* * *}$ & $0.561^{* * *}$ & $0.573^{* * *}$ \\
Physical Ability & $0.488^{* *}$ & $0.518^{* * *}$ & $0.483^{* * *}$ \\
Discomfort & $0.627^{* * *}$ & $0.627^{* * *}$ & $0.720^{* * *}$ \\
Sleep disturbance & $0.523^{* * *}$ & $0.512^{* * *}$ & $0.509^{* * *}$ \\
Dealing with the disease & $0.341^{*}$ & $0.369^{* *}$ & $0.368^{* *}$ \\
Anxiety/Fear/Uncertainty & $0.420^{* *}$ & $0.378^{* *}$ & $0.384^{* *}$ \\
Embarrassment and/or shame & $0.339^{*}$ & $0.357^{* *}$ & $0.406^{* *}$ \\
Social Participation & $0.604^{* * *}$ & $0.620^{* * *}$ & $0.516^{* * *}$ \\
Depression & $0.458^{* * *}$ & $0.369^{* *}$ & $0.410^{* *}$ \\
Total & $0.671^{* * *}$ & $0.645^{* * *}$ & $0.683^{* * *}$ \\
\hline ASDAS-CRP Ankyosing Sppndifis Dise Activy Scor & $-C$ Reactive Protn
\end{tabular}

ASDAS-CRP Ankylosing Spondylitis Disease Activity Score - C Reactive Protein, ASDAS-ESR Ankylosing Spondylitis Disease Activity Score - Erythrocyte Sedimentation Rate, BASDAl Bath Ankylosing Spondylitis Disease Activity ${ }^{*} p<0,05 ;{ }^{* *} p<0,01 ;{ }^{* * *} p<0,001$

Among the available tools, DAPSA and MDA stand out, both as possible treatment targets for PsA [36].

The MDA differentiates itself by being a multidimensional tool, covering several domains of PsA (including the skin), being viable in clinical practice, as it encompasses the multiple forms of presentation of the disease in a broader way. Even so, the MDA does not have a specific measure of the impact of $\mathrm{PHC}$ on the patient, in addition to not assessing the axial involvement that could be frequent and relevant, as demonstrated by our data [18].

Interestingly, in our study, all domains of PsAID-12 and their total score correlated significantly with the DAPSA score and the status of the MDA. MDA and VLDA patients had a significantly lower impact of the disease than those who did not reach MDA.

In addition to the association with MDA, PsAID-12, even though it is a disease impact measure, was positively associated with the scores of peripheral disease activity (DAPSA and DAS28-ESR) and axial disease (ASDAS and BASDAI), which are not evaluated by the MDA. In contrast, the presence of radiographic damage did not correlate significantly with PsAID- 12 .

These findings corroborate the idea that PsAID-12 could be inserted into clinical practice, along with DAPSA index or MDA status, to define disease activity and target treatment in a shared way with the patient. Data from the Re-Flap study has already shown good agreement of the state of remission defined by DAPSA with the patient's opinion [37].

This combination would comply with GRAPPA's recent treatment recommendations, which emphasize that the optimal clinical evaluation of PsA should include PROM along with objective metrics validated to the PsA [38]. In our series, analysis of the association of PsAID12 with clinical variables showed that obesity (defined by BMI $>30 \mathrm{~kg} / \mathrm{m}^{2}$ ) was present in one third of individuals. Obesity predicts a greater chance of developing PsA both in the general population and in individuals with $\mathrm{PsO}$ [39] and is considered a predictor of worse

Table 5 Statistical association between PSAID-12 and MDA

\begin{tabular}{|c|c|c|c|c|}
\hline \multirow[t]{2}{*}{ Domains PsAID } & \multirow{2}{*}{$\begin{array}{l}\text { Non-MDA } \\
\text { Median } \\
\text { (P25-P75) }\end{array}$} & \multirow{2}{*}{$\begin{array}{l}\text { MDA } \\
\text { Median } \\
\text { (P25-P75) }\end{array}$} & \multirow{2}{*}{$\begin{array}{l}\text { VLDA } \\
\text { Median } \\
\text { (P25-P75) }\end{array}$} & \multirow[t]{2}{*}{$p^{*}$} \\
\hline & & & & \\
\hline Pains & $6(3-8)^{c}$ & $3(1-5)^{b}$ & $0(0-0.5)^{\mathrm{a}}$ & $<0.001$ \\
\hline Fatigue/Tiredness & $5(3-7.8)^{b}$ & $2(1.5-4.5)^{\mathrm{a}}$ & $0(0-1.5)^{\mathrm{a}}$ & $<0.001$ \\
\hline Skin Problems & $4(1.3-6.8)^{b}$ & $1(0-2.5)^{\mathrm{a}}$ & $0(0-3)^{a}$ & $<0.001$ \\
\hline Work and/or leisure activity & $5(2-8)^{b}$ & $2(0-4)^{a}$ & $0(0-0)^{\mathrm{a}}$ & $<0.001$ \\
\hline Physical Ability & $6(3-8)^{b}$ & $3(1-5)^{a}$ & $0.5(0-1)^{\mathrm{a}}$ & $<0.001$ \\
\hline Discomfort & $5(3-8)^{b}$ & $2(0.5-4)^{a}$ & $0(0-0.3)^{a}$ & $<0.001$ \\
\hline Sleep disturbance & $3(0.3-7)^{b}$ & $1(0-3)^{\mathrm{ab}}$ & $0(0-0)^{\mathrm{a}}$ & $<0.001$ \\
\hline Dealing with the disease & $4.5(2-6)^{b}$ & $2(0-3)^{a}$ & $0(0-1)^{\mathrm{a}}$ & $<0.001$ \\
\hline Anxiety/Fear/Uncertainty & $5(2.3-8)^{b}$ & $2(0-4.5)^{a}$ & $0(0-0.3)^{a}$ & $<0.001$ \\
\hline Embarrassment and/or shame & $2(0-5)^{b}$ & $0(0-1.5)^{\mathrm{ab}}$ & $0(0-0)^{\mathrm{a}}$ & $<0.001$ \\
\hline Social Participation & $2(0-5.8)^{b}$ & $0(0-1.5)^{\mathrm{a}}$ & $0(0-0)^{\mathrm{a}}$ & $<0.001$ \\
\hline Depression & $2.5(0-6)^{b}$ & $1(0-2)^{\mathrm{ab}}$ & $0(0-0)^{a}$ & $<0.001$ \\
\hline Total score & $4.7(3.0-6.4)^{c}$ & $2.2(1.4-3.6)^{b}$ & $0.5(0.2-0.9)^{a}$ & $<0.001$ \\
\hline Total PsAID $\leq 4-\mathrm{n}(\%)$ & $44(42.3)^{a}$ & $18(85.7)^{\mathrm{b}}$ & $14(100)^{b}$ & $<0.001$ \\
\hline
\end{tabular}

PSAID Psoriatic Arthritis Impact of Disease, MDA Minimal Disease Activity, VLDA Very Low Disease Activity

"Kruskal-Wallis test; a, b, c Equal letters don't differ by the Dunn test or residuals adjusted at $5 \%$ significance 
treatment response and outcome in patients with psoriatic disease [40]. Furthermore, it has also been shown that obesity is a negative predictor for achieving and maintaining MDA status [41].

We found a statistically significant positive association of BMI with the total score and with the following PsAID-12 domains score: pain, fatigue, difficulty for work and/or leisure, physical capacity, discomfort, social participation and depression. This may be related to poorer treatment response in obese patients and/or to the impact of obesity itself on patients' quality of life.

Fibromyalgia coexistence is, in general, a factor that complicates the diagnosis and evaluation of inflammatory rheumatic diseases. Data from the literature indicate that it strongly influences several components of the disease activity scores that involve the opinion of the patient, compromising the interpretation and applicability of these instruments in clinical practice [42].

In the validation study of the Italian version of the PsAID, fibromyalgia was present in $18.7 \%$ of the patients and interfered in the total PsAID-12 score. Patients with fibromyalgia had a higher total PsAID score than those without fibromyalgia [31].

In our study, a similar percentage of individuals presented fibromyalgia (17.5\%), however this comorbidity not significantly interferinge in the total PsAID-12 score, only the pain domain was significantly higher in the group of patients with fibromyalgia. This finding could be quite relevant for the interpretation of PsAID-12 in clinical pratice. However, until this relationship is better studied, fibromyalgia should always be investigated in patients with PsA, for a more adequate interpretation of the disease assessment instruments.

The streghts of our study are related to the consistent sample, the complete evaluation of the patients with a wide number of objective and subjective instruments and the expertise of academic centers investigators.

The main limitation of this study is its transversal design, which did not allow evaluating the sensitivity of PsAID-12 to change.

\section{Conclusion}

The Brazilian Portuguese version of PsAID-12 was shown to be a questionnaire that can be answered by patients with various educational levels and to be a reliable and valid measure of the impact of the disease in patients with PsA.

We demonstrated the utility of PsAID-12 in clinical practice, based on its association with DAPSA, MDA and other assessment scores of both peripheral (DAS28ESR) and axial (ASDAS and BASDAI) disease activity.

From these results, we support the joint use of MDA or alternatively DAPSA with PsAID-12 in clinical practice as complementary tools in the evaluation of the patient with PsA.

\section{Abbreviations}

ASDAS: Ankylosing Spondylitis Disease Activity Score; ATP III: Adult Treatment Panel III; BASDAl: Bath Ankylosing Spondylitis Disease Activity Index; BMI Body: Mass Index; BSA: Body Surface Area; CASPAR: Classification criteria for Psoriatic Arthritis; CRP: Quantitative C - Reactive Protein; DAS28: Disease Activity Score 28 joints; DLQI: Dermatology Life Quality Index; DM: Diabetes Mellitus; ESR: Erythrocyte Sedimentation Rate $(\mathrm{mm} / \mathrm{h})$; EULAR: European League Against Rheumatism; GRAPPA: Group for Research and Assessment of Psoriasis and Psoriatic Arthritis; HAQ-DI: Health Assessment Questionnaire-Disability Index; ICC: Intraclass Correlation Coefficient; MDA: Index Minimum Disease Activity; MS: Metabolic Syndromes; NCEP: National Cholesterol Education Program; PASI: Psoriasis Area Severity Index; PROM: Patient-Reported Outcome Measures; PsA: Psoriatic arthritis; PsAID: Psoriatic Arthritis Impact of Disease; PsAID-9: Psoriatic Arthritis Impact of Disease nine domains; PSAID-12: Psoriatic Arthritis Impact of Disease twelve domains; PsO: Psoriasis; SAH: Sistemic Arterial Hypertension; SF36: Medical Outcome Study 36-item Short Form Health Survey; SPAR CC: Spondyloarthritis Research Consortium of Canada Enthesitis Index; VAS pain: Visual Analogue Scale of $10 \mathrm{~cm}$ for pain; VAS Overall Patient: Visual Analogue Scale of $10 \mathrm{~cm}$ for Overall Evaluation of the Disease; VLDA status: Very Low Disease Activity

\section{Acknowledgments}

We thank the patients who agreed to participate in this study.

\section{Authors' contributions}

All authors were involved in revising it critically for important intellectual content and all authors approved the final version to be submitted for publication. The authors Cruz and Ranza had full access to all study data and takes responsibility for the integrity of the data. Study conception and design: Cruz and Ranza. Acquisition of data: Cruz, Silva Carneiro, Yazbek, Menin, Campanholo, Nascimento Carneiro, Silva, Ranza.

\section{Funding}

No funding was received.

\section{Availability of data and materials \\ The data that support the findings of this study are available from the corresponding author, upon reasonable request.}

\section{Ethics approval and consent to participate}

We declare that this study was approved by the appropriate ethics committee and was therefore conducted in accordance with the ethical standards set forth in the 1964 Declaration of Helsinki and its subsequent amendments. All patients gave their informed consent prior to their inclusion in the study. Details that may reveal the identity of the subjects under study have been omitted.

\section{Consent for publication}

All authors are aware of the full content of the manuscript and provided consent for the submission to Advances in Rheumatology.

\section{Competing interests}

The authors declare that they have no competing interests.

\section{Author details}

${ }^{1}$ Department of Rheumatology, Federal University of Uberlândia, Av. Mato Grosso, 3395, 302, Umuarama, Uberlândia, Minas Gerais 38405-314, Brazil. ${ }^{2}$ Hospital Pedro Ernesto, University of the State of Rio de Janeiro, Rio de Janeiro, Brazil. ${ }^{3}$ Hospital of Clinics, State University of Campinas, Campinas, Brazil. ${ }^{4}$ Faculty of Medicine of São José do Rio Preto, São Paulo, São José do Rio Preto, Brazil. ${ }^{5}$ Faculty of Medical Sciences of Santa Casa de São Paulo, São Paulo, Brazil. ${ }^{6}$ Federal District Base Hospital, Brasília, Brazil.

Received: 23 March 2020 Accepted: 21 August 2020

Published online: 22 September 2020

\section{References}

1. Ranza R, Carneiro S, Qureshi AA, Martins G, Rodrigues JJ, ROmiti R, et al. Prevalence of psoriatic arthritis in a large cohort of brazilian patients with psoriasis. J Rheumatol. 2015;42:829-34. 
2. Moverley AR, Vinall-Collier KA, Helliwell PS. It's not just the joints, it's the whole thing: qualitative analysis of patients' experience of flare in psoriatic arthritis. Rheumatology (Oxford). 2015;54:1448-53.

3. Favarato MHS, Mease P, Gonçalves CR, Gonçalves SC, Sampaio-Barros PD, Goldenstein-Schainberg C. Hypertension and diabetes significantly enhance the risk of cardiovascular disease in patients with psoriatic arthritis. Clin Exp Rheumatol. 2014:32:182-7.

4. Ogdie A, Schwartzman S, Eder L, Maharaj AB, Zisman D, Raychaudhuri SP, et al. Comprehensive treatment of psoriatic arthritis: managing comorbidities and extraarticular manifestations. J Rheumatol. 2014;41:2315-22.

5. Rosen CF, Mussani F, Chandran V, Eder L, Thavaneswaran A, Gladman DD Patients with psoriatic arthritis have worse quality of life than those with psoriasis alone. Rheumatology (Oxford). 2012;51:571-6.

6. Salaffi F, Carotti M, Gasparini S, Intorcia M, Grassi W. The health-related quality of life in rheumatoid arthritis, ankylosing spondylitis, and psoriatic arthritis: a comparison with a selected sample of healthy people. Health Qual Life Outcomes. 2009;7:25.

7. Kavanaugh A, Helliwell P, Ritchlin CT. Psoriatic arthritis and burden of disease: patient perspectives from the population-based multinational assessment of psoriasis and psoriatic arthritis (MAPP) survey. Rheumatol Ther. 2016;3:91-102.

8. Gossec L, de Wit M, Kiltz U, Braun J, Kalyoncu U, Scrivo R, et al. A patientderived and patient-reported outcome measure for assessing psoriatic arthritis: elaboration and preliminary validation of the psoriatic arthritis impact of disease (PsAID) questionnarire, a 13-country EULAR iniciative. Ann Rheum Dis. 2014;73:1012-9.

9. Smolen JS, Braun J, Dougados M, Emery P, Fitzgerald O, Helliwell P, et al Treating spondyloarthritis, including ankylosing spondylitis and psoriatic arthritis, to target: recommendations of an international task force. Ann Rheum Dis. 2014;73:6-16.

10. Eder L, Thavaneswaran A, Chandran V, Cook R, Gladman DD. Factors explaining the discrepancy between physician and patient global assessment of joint and skin disease activity in psoriatic arthritis patients. Arthritis Care Res. 2015;67:264-72

11. Kirwan JR, Bartlett SJ, Beaton DE, Boers M, Bosworth A, Brooks PM, et al. Updating the OMERACT filter: implications for patient-reported outcomes. J Rheumatol. 2014;41:1011-5.

12. Acquadro C, Berzon R, Dubois D, Leidy NK, Marquis P, Revicki D, et al. Incorporating the patient's perspective into drug development and communication: an ad hoc task force report of the patient-reported outcomes (PRO) Harmonization Group meeting at the Food and Drug Administration, February 16, 2001. Value Health. 2003;6:522-31.

13. Scoggins JF, Patrick DL. The use of patient-reported outcomes instruments in registered clinical trials: evidence from ClinicalTrials.gov. Contemp Clin Trials. 2009:30:289-92.

14. Brodszky V, Péntek M, Bálint PV, Géher P, Hajdu O, Hodinka L, et al. Comparison of the Psoriatic Arthritis Quality of Life (PsAQoL) questionnaire, the functional status (HAQ) and utility (EQ-5D) measures in psoriatic arthritis: results from a cross-sectional survey. Scand J Rheumatol. 2010;39:303-9.

15. www.eular.org. The European League Against Rheumatism. PsAID Psoriatic arthitis impact of disease. [cited 2018 Jul 13]. Available from: http:// pitie-salpetriere.aphp.fr/psaid/raid_psaid_quest_home.php.

16. Wild D, Grove A, Martin M, Eremenco S, McElroy S, Verjee-Lorenz A, et al. Principles of good practice for the translation and cultural adaptation process for patient-reported outcomes (PRO) measures: report of the ISPOR Task Force for Translation and Cultural Adaptation. Value Health. 2005:8:94-104.

17. Tillett W. Composite measures of impact and activity in psoriatic arthritis: a conceptual framework [editorial]. J Rheumatol. 2017;44:268-70.

18. Gossec L, McGonagle D, Korotaeva T, Lubrano E, Miguel E, Østergaard M, et al. Minimal disease activity as a treatment target in psoriatic arthritis: a review of the literature. J Rheumatol. 2018;45:6-13.

19. Taylor W, Gladman D, Helliwell P, Marchesoni A, Mease P, Mielants H, et al. Classification criteria for psoriatic arthritis: development of new criteria from a large international study. Arthritis Rheum. 2006;54:2665-73.

20. Expert panel on detection, evaluation, and treatment of high blood cholesterol in adults. Executive summary of the third report of the national cholesterol education program (NCEP) expert panel on detection, evaluation, and treatment of high blood cholesterol in adults (Adult Treatment Panel III). JAMA 2001; 285:2486-2497.

21. Grundy SM, Cleeman JI, Daniels SR, Donato KA, Eckel RH, Franklin BA, et al. Diagnosis and management of the metabolic syndrome: an American Heart
Association/National Heart, Lung, and Blood Institute Scientific Statement. Circulation. 2005;112:2735-52.

22. Ciconelli RM, Ferraz MB, Santos W, Meinão I, Quaresma MR. Tradução para a língua portuguesa e validação do questionário genérico de avaliação de qualidade de vida SF-36 (Brasil SF-36). Rev Bras Reumatol. 1999;39:143-50.

23. Ferraz MB, Oliveira LM, Araujo PM, Atra E, Tugwell P. Crosscultural reliability of the physical ability dimensions of the health assessment questionnaire. J Rheumatol. 1990;17:813-7.

24. Martins GA, Arruda L, Mugnaini ASB. Validação de questionários de avaliação da qualidade de vida em pacientes de psoríase. Validation of life quality questionnaires for psoriasis patients. An Bras Dermatol. 2004;79:521-35.

25. Maksymowych WP, Mallon C, Morrow S, Shojania K, Olszynski WP, Wong RL, et al. Development and validation of the Spondyloarthritis research consortium of Canada (SPARCC) Enthesitis index. Ann Rheum Dis. 2009;68:948-53.

26. Carlin CS, Feldman SR, Krueger JG, Menter A, Krueger GG. A 50\% reduction in the psoriasis area and severity score (PASI 50) is a clinically significant endpoint in the assessment of psoriasis. J Am Acad Dermatol. 2004;50:859-66.

27. Schoels M, Aletaha D, Funovits J, Kavanaugh A, Baker D, Smolen JS. Application of the DAREA/DAPSA score for assessment of disease activity in psoriatic arthritis. Ann Rheum Dis. 2010;69:1441-7.

28. Sellas IFA, Juanola RX, Ruiz A, Rosas J, Medina JL, Collantes EE, et al. Clinical utility of the ASDAS index in comparison with BASDAI in patients with ankylosing spondylitis (Axis Study). Rheumatol Int. 2017;37:1817-23.

29. Terwee CB, Bot SD, de Boer MR, van der Windt DA, Knol DL, Dekker J, et al. Quality criteria were proposed for measurement properties of health status questionnaires. J Clin Epidemiol. 2007;60:34-42.

30. Hair JF, Anderson RE, Tatham RL, Black WC. Multivariate data analysis. New Jersey: Prentice-Hall; 1999.

31. Di Carlo M, Becciolini A, Lato V, Crotti C, Favalli EG, Salaffi F. The 12-item psoriatic arthritis impact of disease questionnaire: construct validity, reliability, and interpretability in a clinical setting. J Rheumatol. 2017:44:279-85.

32. Holland R, Tillett W, Korendowych E, Cavill C, Waldron N, Brooke M, et al. Validation of the psoriatic arthritis impact of disease (PSAID) questionnaire and its potential as a singleitem outcome measure in clinical practice. Ann Rheum Dis. 2018;77:343-7.

33. Chang ES, Beck T, Simon MA, Dong X. A psychometric assessment of the psychological and social well-being indicators in the PINE study. J Aging Health. 2014;26:1116-36

34. Schmitt J, Ford DE. Psoriasis is independently associated with psychiatric morbidity and adverse cardiovascular risk factors, but not with cardiovascular events in a population-based sample. J Eur Acad Dermatol Venereol. 2010;24:885-92.

35. Dommasch ED, Li T, Okereke OI, Li Y, Qureshi AA, Cho E. Risk of depression in women with psoriasis: a cohort study. Br J Dermatol. 2015;173:975-80.

36. Smolen J, Schöls M, Braun J, Dougados M, FitzGerald O, Gladman D, et al. Treating axial spondyloarthritis and peripheral spondyloarthritis, especially psoriatic arthritis, to target: 2017 update of recommendations by an international task force. Ann Rheum Dis. 2018:77:3-17.

37. Gorlier C, Orbai AM, Puyraimond-Zemmour D, Coates L, Kiltz C, Leung Y, Palominos $\mathrm{P}$, et al. Comparing patient-perceived and physician-perceived remission and low disease activity in psoriatic arthritis: an analysis of 410 patients from 14 countries. Ann Rheum Dis. 2019;78:201-8.

38. Coates LC, Kavanaugh A, Mease PJ, Soriano ER, Laura Acosta-Felquer M, Armstrong AW, et al. Group for research and assessment of psoriasis and psoriatic arthritis 2015 treatment recommendations for psoriatic arthritis. Arthritis Rheumatol. 2016;68:1060-71.

39. Love TJ, Zhu Y, Zhang Y, Wall-Burns L, Ogdie A, Gelfand JM, et al. Obesity and the risk of psoriatic arthritis: a population-based study. Ann Rheum Dis. 2012;71:1273-7.

40. Eder L, Thavaneswaran A, Chandran V, Cook R, Gladman DD. Increased burden of inflammation over time is associated with the extent of atherosclerotic plaques in patients with psoriatic arthritis. Ann Rheum Dis. 2015;74:1830-5.

41. di Minno MN, Peluso R, lervolino S, Lupoli R, Russolillo A, Scarpa R, et al. Obesity and the prediction of minimal disease activity: a prospective study in psoriatic arthritis. Arthritis Care Res. 2013:65:141-7.

42. Dougados M, Perrot S. Fibromyalgia and central sensitization in chronic inflammatory joint diseases [editorial]. Joint Bone Spine. 2017;84:511-3.

\section{Publisher's Note}

Springer Nature remains neutral with regard to jurisdictional claims in published maps and institutional affiliations. 